\title{
A INFLUÊNCIA DO USO DA INTERNET NAS AGÊNCIAS DE VIAGENS DAS PRINCIPAIS CIDADES DO EIXO LONDRINA-APUCARANA
}

\author{
Elizabeth Wood Moçato de Oliveira ${ }^{1}$, Giane Reis da Silva ${ }^{2}$ \\ ${ }^{1}$ Mestranda em Administração da Universidade Estadual de Londrina (UEL) - bete mocato@ hotmail.com. ${ }^{2}$ Graduada em Turismo \\ pela Faculdade Estadual de Ciências Econômicas de Apucarana - gianeprevital@hotmail.com
}

\section{RESUMO}

As agências de viagens foram consideravelmente afetadas pelo advento da internet, tecnologia que influenciou o modo de trabalhar das agências, facilitando seu cotidiano, mas também passou a oferecer meios de comprar produtos turísticos via web, o que eventualmente pode acarretar perdas de vendas por parte das agências. Pensando nesta situação, o presente estudo busca levantar de que modo a internet influenciou nas atividades das agências de viagens e se essa influência é negativa ou positiva.

Palavras - chave: agências de viagens; internet, influência do uso da internet nas agências de viagens.

THE INFLUENCE OF INTERNET USE IN TRAVEL AGENCIES OF THE MAJOR CITIES OF SHAFT LONDRINA-APUCARANA

\begin{abstract}
Travel agencies were considerably affected by the advent of internet, technology influenced the way of working of the agencies, facilitating their daily lives, but also started to provide the means to buy tourism products via the web, which can eventually lead to loss of sales by the agencies. Thinking about this situation, this study raises some how the internet influenced the activities of travel agencies and this influence is positive or negative.

Keywords: travel agencies, internet, influence the use of the internet on travel agencies.
\end{abstract}




\section{INTRODUÇÃO}

Sabe-se que a internet mudou em muito a vida das pessoas, conectando-as a diferentes possibilidades e vivências, que antes de seu uso não eram exploradas. As redes de computadores estão se ampliando para atingir companhias de maneiras até então inimagináveis, transformando a natureza das interações comerciais e levantando questões de extrema relevância sobre estratégias de negócios (TAPSCOTT, 1997 apud VICENTIN; HOPPEN, 2003).

Neste ambiente eletrônico desenvolve-se não só a pesquisa de novas experiências, produtos e serviços, como também seu comércio, o chamado comércio eletrônico, que disponibiliza amplamente informações de maneira rápida e fácil, sendo assim constitui-se em instrumento estratégico que pode ser utilizado como diferencial competitivo no mercado de pequenas, médias e grandes empresas.

Os produtos e serviços disponibilizados para compra na internet são bastante variados, além de possibilitar o acesso a vários sites de venda, disponíveis vinte e quatro horas por dia, durante o ano todo. Portanto o uso da mesma, impacta diferentes nichos mercadológicos.

No caso de agências de viagens, esta ferramenta trouxe grandes avanços e mudanças, que podem ser consideradas como aspectos negativos ou positivos. A quem diga que o uso da internet para compra de serviços turísticos é de baixa qualidade, pois nem sempre a imagem ofertada é a mesma que é vendida, por isso preferem a agência tradicional que tem o fator humano como condição de confiança e comodidade, visto que oferece transporte, acomodações e excursões, como também plano de viagens para clientes, fornecem conselhos e informações especializadas sobre destinos, e outras informações de viagens relacionadas (DICKMAN, 1989 apud FLECHA et al., 2006). As agências de viagens sofrem e ainda sofrerão com transformações irreversíveis advindas da tecnologia e por isso devem estar cada dia mais cientes das ameaças e oportunidades que giram em torno de seus negócios, para que tenham postura adequada frente às conseqüências dessa nova realidade.

Desta forma este estudo justifica-se pela relevância do assunto para o conhecimento dos fatores positivos e negativos acarretados pelo uso da internet por agentes de viagens e consumidores de serviços turísticos, possibilitando assim que agências de viagem utilizem-se dessas informações para melhoria e crescimento de seus serviços.

Por ser um tema recente, ainda pouco estudado por acadêmicos da área de turismo, o presente trabalho poderá se tornar fonte de pesquisa e base de novos estudos a fim de conhecer, analisar e melhorar o setor de viagens e turismo, bem como sua prestação de serviços, além de identificar prejuízos e ganhos de mercado.

\section{INTERNET}

A internet é uma rede global que conecta milhões de computadores a milhões de pessoas (HARLEY; STOUT, 1995 apud VICENTIN; HOPPEN, 2003), e é hoje a maior rede de computadores do mundo.

Segundo o site da Discovery Brasil, os números do seu crescimento não param de surpreender, especula-se que até o ano de 2015 haverá mais de dois bilhões de usuários.

A internet começou no Brasil em 1991, de forma experimental, com a Rede Nacional de Pesquisa, mas somente em 1995 com a intervenção do Ministério das Telecomunicações e Ministério da Ciência e Tecnologia, a população do país teve acesso a está tecnologia.

De quando a internet começou no Brasil até hoje, muita coisa mudou, a velocidade, a 
forma de acesso e naturalmente a sua popularidade.

De acordo com o Ibope Nielsen Online em dezembro de 2009, o número de internautas havia crescido $16 \%$ em relação a 2008 , e o Brasil é $05^{\circ}$ país com o maior número de conexões à internet.

Segundo Alexandre Sanches Magalhães, gerente de análise do Ibope, o ritmo de crescimento da internet brasileira é intenso. A entrada da classe $\mathrm{C}$ para o clube dos internautas deve continuar a manter esse mesmo compasso forte de aumento no número de usuários residenciais.

Segundo Antonioli (2010), este crescimento constante do uso da internet também se reflete no número de compras on-line, que no ano de 2008 equivaleram a $\mathrm{R} \$$ 8,2 bilhões.

Esta explosão está muito ligada ao uso comercial da internet, pois os negócios que vão desde a simples compra de um livro, carro ou mesmo apartamento, até complexas aplicações no mercado de capitais podem ser feitas de qualquer computador conectado à internet.

Para Turban (apud VICENTIN; HOPPEN, 2003), o uso do comércio eletrônico traz benefícios para consumidores e empresas, já que possibilita verificar vários sites de venda, fazer rápidas comparações de preços e produtos, promove a concorrência, aumenta o mercado de atuação, bem como diminui custos de criação, venda e distribuição de produtos e serviços.

De acordo com o autor, ainda existem barreiras para o maior avanço do comércio eletrônico, como: falta de confiança, não capacidade das telecomunicações, não integração de softwares e também a falta de conhecimento da população.

Ainda assim, a internet é uma ferramenta de grande uso, e se tornou o terceiro veículo de comunicação de maior alcance no Brasil, atrás apenas de rádio e TV. Segundo Antonioli (2010), atualmente cerca de $87 \%$ dos internautas utilizam e confiam na rede para pesquisar produtos e serviços.

Sem dúvida que hoje em dia a internet desempenha um papel fundamental na sociedade, tendo várias utilidades, entre elas servir como um meio de comunicação essencial, grande fonte de informação, a maior do mundo.

Este meio de comunicação, que traz informações de diversos assuntos, e permite angariá-las a qualquer momento, de forma que se pode obter dados de qualquer tema através desta ferramenta.

Além de proporcionar a troca de informações e dados, a internet serve também como meio de fazer compras. Muitos sites possibilitam este tipo de serviço.

No setor turístico muitos são os sites que dispõem desta opção, e estes apresentam muitas vezes preços bastante competitivos, tornando-se assim uma concorrência para as agências de viagens físicas.

\section{AGÊNCIAS}

As agências de viagens são organizações que visam assegurar uma viagem tranqüila e sem transtornos ao turista, para isso contam com profissionais treinados para organizar pacotes de viagens incluindo opções como hotel, transporte, lazer, cultura, dentre outros.

Segundo Andrade (1995 apud MAMEDE, sd), as agências podem ser divididas em duas categorias: agências de viagens e agências de viagens e turismo.

Segundo o autor as agências de viagens "são aquelas que prestam serviços a seus usuários em território brasileiro e em países limítrofes, quando em função da complementação de viagens e por tempo limitado". Está prestadora de serviços é em suma uma intermediária entre a oferta e a demanda. 
As agências de viagens são fundamentalmente empresas em que o seu principal serviço é a intermediação, sendo, dessa forma, de extrema importância 0 atendimento para a sua sobrevivência no mercado atual. É neste atendimento, ou seja, no contato com os hotéis, com as companhias aéreas e com os outros prestadores de serviços turísticos que se pratica a interface e se corporifica, por meio do consumo, a atividade turística (DANTAS, 2002, p. 22).

Para Beni (2001), a atuação das agências de viagens se resume nos aspectos de assessoramento do cliente quanto a esclarecimentos necessários a respeito de qualquer aspecto relativo á viagem; organização da viagem, garantindo que tudo o que foi solicitado pelo cliente será fornecido e promoção que traduz em promover as localidades $e$ insumos que compõem o pacote turístico intermediado por ela.

Mais especificamente, Beni (2001, p.190) descreve as atividades de uma agência de viagens como

[...] venda comissionada ou intermediação remunerada de passagens individuais ou coletivas, passeios, viagens e excursões; intermediação remunerada na reserva de alojamento; recepção, translado, transferência e assistência especializada ao turista; operação de viagens e excursões, individuais ou coletivas, compreendendo a organização, contratação e execução de programas, roteiros e itinerários; credenciamento de empresas transportadoras, empresas de hospedagem para emissão de bilhetes, vouchers, e outras prestações de serviços turísticos; divulgação pelos meios adequados, inclusive propaganda e publicidade, de todos os serviços.

São consideradas o elo entre o cliente e o fornecedor de serviços, já que são elas que comercializam passagens aéreas, aluguel de veículos, reservas de hotéis, seguros de viagens, além de prestarem serviços relativos à documentação de viagens, câmbio e venda de pacotes nacionais e internacionais (PETROCCHI; BONA, 2003).

Sendo assim funcionam como um suporte ao turista que quer adquirir serviços turísticos já estruturados e seguros a fim de usufruir da aquisição sem preocupações no momento de pré, trans, e pós viagem, sendo assim garantida sua satisfação.

Já as agências de viagens e turismo são empresas que planejam, organizam e coordenam viagens por meio da contratação de diferentes fornecedores de produtos turísticos.

De acordo com Andrade (1995 apud MAMEDE, sd), "são aquelas que prestam serviço não apenas ao público consumidor, mas também às próprias agências de turismo, tanto no Brasil quanto no exterior."

Tomelin (2001) ressalta que somente a categoria agência de viagens e turismo teria permissão para organizar roteiros e itinerários de viagens e excursões, coletivas ou individuais, para o exterior. Por sua vez, as agências de viagens podem operar viagens nacionais e as internacionais somente por via rodoviária.

Andrade (2001) coloca que as agências de viagens e turismo podem também ser denominadas como operadoras turísticas, as quais se restringem apenas às funções de criadoras de programas e fornecedoras de pacotes e planejamentos a serem comercializados pelas agências de viagem.

Segundo Petrocchi e Bona (2003) todos os produtos ou serviços, do pacote sejam 
realizados por terceiros, cabe a operadora a iniciativa de reuni-los, planejar a viagem, responsabilizar-se pelo conjunto dos serviços oferecidos, comercializar o pacote e coordenar sua operacionalizações.

Portanto, as agências de viagens e turismo se diferem basicamente das agências de viagens pelo fato de que a primeira fornece 0 produto às agências de viagens, e estas por sua vez, vendem ao consumidor final.

\section{INFLUÊNCIA DA INTERNET EM AGÊNCIAS DE VIAGENS}

Para Vicentin e Hoppen (2003) a internet, que surgiu como um grande canal de divulgação e vendas de produtos e serviços, tem mudado a forma como as pessoas se comunicam, tornando muito eficaz o acesso e troca de informações. Cada vez mais as pessoas têm acesso a variados dados e adquirem produtos turísticos através da rede.

A revolução da internet esta causando um impacto fundamental e profundo na maneira como as viagens e os serviços complementares são anunciados, distribuídos, vendidos e entregues, simplesmente porque negócio real por trás de viagens é a informação (VASSOS, 1998).

Barreto aborda que a relação Turismointernet é dialética, visto que está contribuindo para as melhorias nas áreas administrativas, como por exemplo: nas reservas de passagens aéreas, hotéis, pacotes turísticos, na comunicação entre operadores e agentes de viagem, mas, por outro lado, acaba por fazer com que as pessoas fiquem mais em casa, uma vez que permite trazer o mundo para dentro do lar. (BARRETTO, 2000 apud MANTOVANI; SOUZA, 2007).

A internet é uma importante ferramenta de inovação para as empresas, e por ser mecanismo disponível a todos, passa a ser uma ameaça para as agências de turismo, pois possibilita que os clientes planejem sua viagem, façam suas reservas em hotéis, comprem passagens aéreas, efetuem pagamentos, aluguem veículos, ou seja, façam tudo o que precisar sem sair de sua casa.

Para Vicentin e Hoppen (2003) o objetivo de vender produtos e serviços relacionados com essas viagens, a internet entra para fazer um papel fundamental nas agências, pois veio a somar, além de ser um eficiente veículo de propaganda para as viagens e ainda, seu uso melhora o fluxo de trabalho das operadoras, facilitando as reservas em aviões, hotéis e restaurantes, por exemplo. Elas interconectam pessoas para os mais variados fins e têm contribuído para ampliar e democratizar o acesso à informação, eliminando barreiras como distância, fronteiras, fuso horário, etc.

Assim o agente de viagem perdeu 0 papel que detinha antigamente, pois qualquer pessoa hoje pode, em tempo real, fazer suas próprias reservas de passagens aéreas, hotéis, estabelecer sua própria programação no destino a ser visitado, ver oferta de restaurantes, passeios e tudo que se faz importante na visita a uma destinação.

Como conseqüência, as empresas prestadoras de serviços turísticos deixaram de depender de agenciamentos e da necessidade de pagar comissões aos agentes de viagens pelos produtos vendidos.

Outra ameaça aos negócios do setor turístico é: a venda de bilhetes aéreos no varejo por operadoras.

Por um lado, Amorim (2001) destaca que o uso da internet traz aspectos positivos, pois se propõem a aumentar a eficiência dos processos e a produtividade, sem deixar de considerar que com as agências de viagens locais, o cliente cria um vinculo de amizade com alguns agentes, que assim se tornam o seu ponto de contacto cada vez que for realizar uma viagem. 
Segundo o autor, para isso as agências têm grandes benefícios, pois facilitam a comunicação dos produtos, compõem viagens personalizadas, pacotes individualizados, além de vender e intermediar passagens e passeios entre muitos outros serviços, procurando facilitar e resolver problemas dos turistas para que sua viagem seja satisfatória e agradável.

Rapidez na execução do atendimento, facilidades para contatos com o cliente, melhor qualidade, maior segurança na prestação de informação, maior liberdade ao cliente.

Segundo Menezes (2001) a presença de um agente não pode ser desvalorizada, o contato humano é sempre atrativo aos olhos dos consumidores, mas depender da atividade prestada por eles pode não ser cômodo quando se dispõe de pouco tempo, já que podem adquirir serviços turísticos em um site pode ficar no ar a disposição dos clientes vinte e quatro horas por dia facilitando assim a comercialização dos produtos de uma agência.

É necessário que a internet seja utilizada aproveitando todos os seus recursos, como instrumento para agregar valor e gerar economia para o turismo.

Assim a rede mundial de computadores torna-se uma das principais transformações no mundo dos negócios, passando a ter um impacto fundamental no setor turístico, pois é um meio que possibilita um acesso rápido e fácil às informações o que fez surgirem inúmeros sites especializados em comercializar Turismo pela internet.

Segundo 0 site Artigonal este novo conceito em negócios transformou-se em uma ferramenta importante e indispensável, oferecendo aos consumidores subsídios para a escolha de seus próprios roteiros turísticos, de férias ou negócios, que representam investimento de tempo e financeiro, muitas vezes sem precisar passar pela ajuda de um agente de viagem.
As empresas descobriram na internet um excelente caminho para melhorar seus lucros e as vendas dispararam pela comodidade que a mesma causa, transformando a internet em verdadeiras agências on line.

As agências de viagens devem estar atentas às mudanças mercadológicas que estão acontecendo em seu ramo de negócio e assim estarem preparadas para enfrentar mudanças tecnológicas que ajudarão no desenvolvimento de seu trabalho de prestação de serviços turísticos e as manterão atuantes neste segmento, para que assim possam brigar por uma posição no processo turístico.

\section{METODOLOGIA}

Foram realizadas pesquisas científicas de ordem bibliográfica, documental, descritiva, exploratória, indutiva e de campo, de caráter qualitativo e quantitativo, com agentes de viagens e consumidores de serviços turísticos a fim de conhecer melhor o que estes pensam a respeito do uso da internet para a compra de serviços relacionados ao Turismo.

Foram analisados os resultados obtidos através da aplicação dos questionários à amostra que consiste em clientes e agentes das cidades de Londrina, Cambé, Rolândia, Arapongas e Apucarana.

A partir da análise destes questionários foram levantadas as opiniões e hábitos de consumidores de serviços turísticos em relação à internet e também a percepção dos agentes de viagens no que diz respeito às mudanças no comportamento de seu público alvo com 0 crescente uso desta ferramenta. Para isso foram entrevistados agentes das seguintes cidades e agências de viagens: em Londrina foram entrevistadas as agências Vitória Turismo, Giramundo Turismo, Bless Turismo, Aloha, Avenida, Cia de Viagens, Invicta, Navega Tur, Âncora, Valentin, World Study e Yaren Turismo. 
Já em Cambé e Rolândia foram entrevistadas a Voemundo Turismo e a Terrocean, respectivamente, únicas agência das referidas cidades no momento da aplicação dos questionários. Em Arapongas foram contatadas as três agências da cidade, porém só foi obtido êxito de respostas na Valentin e CVC, sendo que a Bella Vista Turismo não respondeu. Por último, em Apucarana, que atualmente conta com seis agências, foram respondidos os questionários em quatro delas: CVC, VMM, Valentin e Daiwa Turismo, já que Etec e Ipanema não contribuíram para a pesquisa.

\section{OPINIÕES DE CONSUMIDORES DE} SERVIÇOS TURÍSTICOS $X$ OPINIÕES DE AGENTES DE VIAGENS DO EIXO ESTUDADO ACERCA DO USO DA INTERNET

Foram feitas quinze perguntas aos duzentos consumidores de serviços turísticos entrevistados nas principais cidades do eixo Londrina-Apucarana. Destas serão apresentados os resultados principais.

Quando indagados se comprariam pacotes de viagens pela internet, 54\% dos entrevistados afirmaram que sim, pela facilidade de compra e de visualizar detalhes, praticidade, rapidez, comodidade, preços melhores e agilidade, dado a falta de burocracia. Ressaltaram também que procuram comprar em sites de empresas conhecidas, pois estes remetem segurança.

Já 46\% do total, responderam negativamente à pergunta por motivos como: falta de confiança, por não acreditar na garantia de compra e na veracidade das informações disponibilizadas, necessidade de ouvir outra pessoa para a troca de idéias, já que a internet não permite o diálogo, presença e pessoalidade, e também por medo de não receber o serviço que adquiriu, por risco de fraudes, falta de hábito e de conhecimento sobre a internet. Também alegaram que comprar em agências é mais interessante já que os agentes cuidam de toda a documentação.

Dos duzentos entrevistados, cento e trinta e um (65\%), responderam que fazer compras de pacotes de viagens ou mesmo passagem aérea pela internet é fácil e seguro, já que esta apresenta várias opções, e quando adquirido em sites de empresas idôneas não apresenta riscos, já que são seguros e auto-explicativos, a forma de pagamento é facilitada, os preços são mais atrativos, é mais cômodo, prático e ágil, otimiza o tempo, já que não é necessário o deslocamento para a realização da compra, e esta pode ser efetivada a qualquer hora.

Sessenta e nove pessoas, que representam 35\% dos entrevistados disseram que este tipo de compra não é fácil e seguro, pois nem todos sabem usar adequadamente a internet, tem medo que aconteçam erros de interpretação, não se sentem à vontade para fazer compras através desta ferramenta e acreditam que esta pode ser um meio de golpes, já que é necessário cadastrar dados pessoais e do cartão de crédito, não sendo desta forma seguro, e acreditam que estão sujeitos a comprar um serviço que não o satisfaçam. Alegam também que comprar em agências é o mais indicado já que são especializadas na prestação deste tipo de serviço, que especificam melhor o produto adquirido, e são confiáveis.

Dos duzentos entrevistados, quarenta e três, ou seja, 22\% já compraram algum pacote turístico pela internet, e cento e cinqüenta e sete, que representam $78 \%$ nunca fizeram este tipo de compra pela web.

Dos que já compram pacotes turísticos pela internet, doze pessoas (28\%) o fizeram apenas uma vez, dezenove (44\%), já compraram duas vezes, cinco pessoas (12\%), três vezes, não houve quem comprou quatro vezes, e sete deles (16\%) já compraram mais de quatro vezes. O 
gráfico abaixo representa os dados referentes a esta questão:

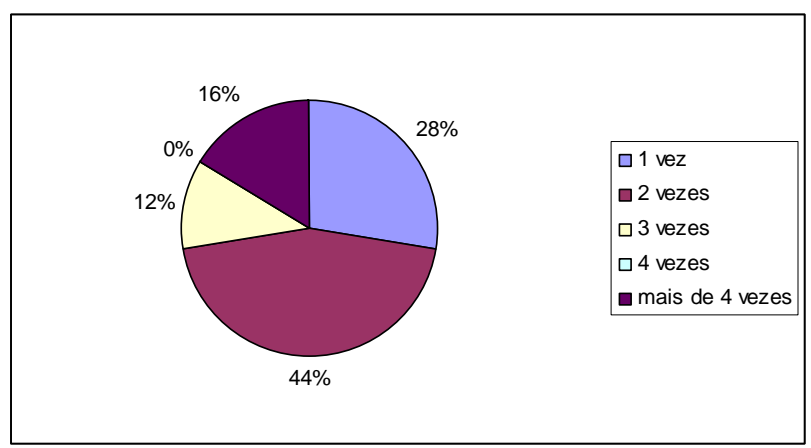

Gráfico 1: Quantas vezes comprou pacote turístico pela internet.

Dos entrevistados, setenta e um já compraram passagens aéreas pela internet, 0 que representa um cenário de 36\%, e cento e vinte e nove (64\%) nunca compraram este serviço pela internet.

Dos 35\% dos entrevistados que declararam que já compraram passagens aéreas pela internet, $18 \%$ deles (treze pessoas), compraram uma vez; $18 \%$ (treze pessoas) compraram duas vezes; $14 \%$ (dez pessoas) compraram por três vezes; 4\% (três pessoas) compraram quatro vezes; e 46\% (trinta e duas pessoas), já compraram mais de quatro vezes. O gráfico a seguir representa está questão:

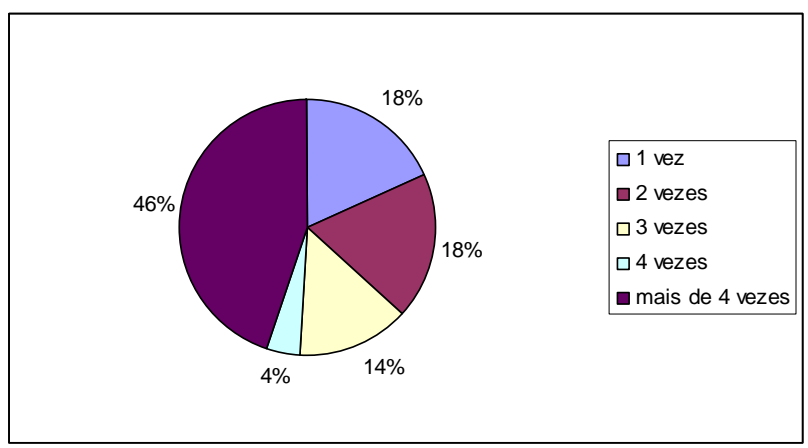

Gráfico 2: Quantas vezes comprou passagem aérea pela internet

Quando perguntados sobre se recomendariam a compra de pacotes ou passagens aéreas pela internet, 60\% dos entrevistados disseram que recomendariam a compra em sites seguros de empresas idôneas, que são organizadas e responsáveis, por ser prático, cômodo, rápido (economizando tempo), fácil, não ter burocracia, ser seguro, possibilitar o esclarecimento de dúvidas navegando pela internet, por ter um preço mais baixo e a forma de interessante.

Já 40\%, não recomendam a compra, pois acreditam não ser seguro, e afirmam que os sites não disponibilizam as informações necessárias para que haja confiança no produto comprado. Alguns entrevistados relataram que usam os sites da internet apenas para consultas prévias, mas que não efetuam a compra através desta ferramenta, e sim em agências que esclarecem melhor as dúvidas, tem credibilidade e garantem o serviço comprado.

Quando perguntados se procuram agências de viagens para realizar viagens, 54\%, o que representa cento e oito dos entrevistados disseram que procuram esta prestadora de serviços; e 46\%, noventa e duas pessoas disseram que não procuram pela agência.

Dos entrevistados que utilizam o serviço das agências de viagens, dezenove (18\%), o fizeram uma única vez; vinte e sete (25\%), duas vezes; dezesseis (15\%), três vezes; sete (6\%), quatro vezes; e trinta e nove (36\%), mais de quatro vezes. Os resultados estão dispostos no gráfico:

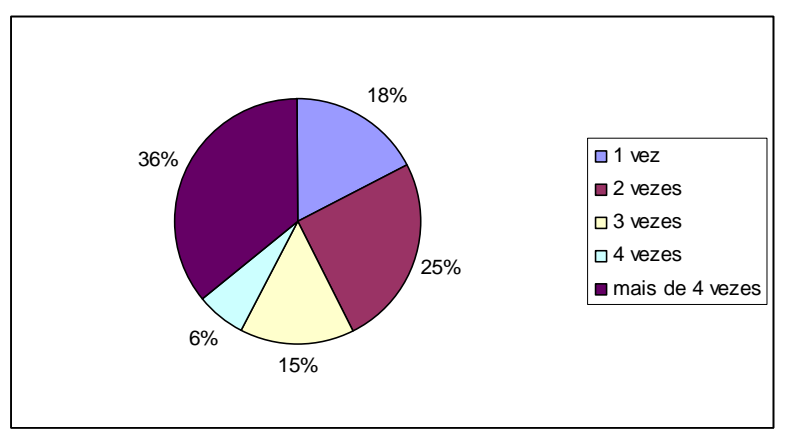

Gráfico 3: Quantas vezes já utilizou os serviços de uma agência.

Cento e oitenta e seis entrevistados (93\% do total) relataram que recomendam os serviços 
das agências de viagens, já que os vendedores são experientes, profissionais, responsáveis e conhecem os roteiros, podendo esclarecer dúvidas com clareza, dar apoio, orientações, dicas e detalhes sobre bares, restaurantes, atratividades, passeios e roteiros que mais se encaixem nas expectativas de seu cliente, já que oferecem atendimento personalizado. Acreditam que seja prático, seguro e mais cômodo, pois os agentes resolvem tudo para o passageiro, inclusive imprevistos e todas as informações e serviços são prestados em um só lugar, parcelados e sem burocracia.

Dos duzentos entrevistados, quatorze, $7 \%$ do total, não recomendam os serviços de agências, pois acreditam ser desnecessários e mais caro.

Visando enriquecer a discussão foram também coletadas as opiniões dos agentes de viagens quanto ao perfil dos consumidores de serviços turísticos.

Os agentes entrevistados responderam a sete perguntas. Quando perguntados se acreditam que o volume de vendas, e conseqüentemente o lucro das agências de viagens vem diminuindo nos últimos anos, os agentes responderam que acreditam na diminuição das vendas por motivos como: diversificação da oferta, ou seja, existem muitas agências, cada uma especializada em um determinado público, ou em um produto específico, o que diminui a quantidade de clientes em cada uma delas, devido ao mercado ser competitivo; o aumento da tecnologia no setor, em que muitas pessoas compram através de portais na internet, onde encontram preços mais baixos já que não contemplam a taxa paga aos agentes de viagens; crescimento de grandes operadoras, como a CVC que são concorrentes de agências. Um dos agentes colocou que acredita na diminuição de lucros, já que a internet tem tarifas mais baixas e muitas pessoas compram por está ferramenta, que oferece todos os serviços que agência presta, e ainda colocou que muitas companhias aéreas diminuíram seu comissionamento e até não comissionam alguns trechos ao agente, o que obriga este a colocar uma comissão por conta própria, o que portanto é diferente em cada agência, o que abre oportunidade para a concorrência e faz diminuir seu lucro. Já outros agentes acreditam que o lucro não diminuiu, pois as pessoas confiam nos agentes e no momento de fechar a compra procuram uma agência. Um dos entrevistados acreditam que 0 volume de vendas vem aumentando, devido a facilidades de pagamento, alta divulgação do produto e preferência pelo contato com os agentes, mas o lucro não aumentou devido as passagens aéreas que tem preços mais baixos na internet.

Quando indagados se os clientes comentam sobre o uso da internet como fonte de pesquisa para levantar informações sobre viagens os agentes colocaram que freqüentemente isso acontece, e que devido à grande diversificação de oferta, os consumidores muitas vezes estão mais informados do que o próprio agente, pois é difícil conhecer todos os hotéis, pacotes, lugares, etc. Outros colocaram que este acesso dos clientes a internet facilita muito a trabalho dos agentes, já que os consumidores já tem muitas informações sobre o lugar que deseja visitar. Colocaram também que os consumidores não só usam a internet para levantar informações, como também realizam as compras por está ferramenta, e quando procuram as agências vão em busca de comparar preços.

Quando perguntados se os clientes encontram preços melhores na internet, colocaram que sim, principalmente quando se refere a passagens aéreas, já que as companhias oferecem preços até dez por cento mais baixo em seus sites, já que neste tipo de compra não precisam comissionar agentes de viagens; hotéis 
as vezes também não possuem política de comissionamento, o que faz com que a agência coloque o lucro sobre a diária. Alguns colocaram que dependendo da compra não compensa para o cliente adquirir pela internet, já que o trabalho é grande, e, portanto eles compram através de agências. Outros colocaram também que a diferença do preço de comprar pela internet ou pela agência é mínima e muitos clientes preferem comprar pela agência, pois acredita ser mais seguro.

Já quando perguntados se já perderam clientes para o mercado virtual, colocaram que sim, já que muitas vezes os consumidores encontram preços melhores pela internet, principalmente passagens aéreas. Algumas acreditam que ao mesmo tempo que perderam clientes também ganharam, já que muitos prezam pelas informações e a confiabilidade das agências, e ainda relatam que muitos clientes que compraram pela internet acabam voltando para as agências já que não tiveram o mesmo atendimento que os agentes prestam, tendo problemas com reembolso e remarcação.

A quinta pergunta foi referente aos diferenciais da agências frente à internet. Os agentes colocaram que buscam explicar minuciosamente a respeito do local visitado, procurando falar da localização de hotéis, dar dicas de passeios, receptivos, ou seja, um serviço informal que a internet não proporciona. Colocaram também que buscam a menor tarifa, e sempre dando suporte ao cliente até o fim da viagem, o que não acontece quando o cliente compra pela internet, já que o serviço não é personalizado, quando acontece um problema o consumidor tem utilizar sistemas de atendimento ao consumidor para resolver questões como remarcação, reembolso, e quando compram pela agência, está resolve este tipo de empecilho. Relatam também a agilidade no atendimento, o suporte da agência, experiência do profissional, e a atenção no pré e pós venda, já que o atendimento é personalizado e visa facilitar a compra para o cliente, como diferenciais da agência de viagens frente à internet. Uma agência física remete credibilidade, e conforto ao cliente, que não precisa se preocupar com pormenores, burocracias, e é acompanhado muitas vezes até no dia do embarque pelo agente.

Quando perguntados se acreditam que o uso da internet poderá extinguir o ramo dos agentes de viagens, alguns responderam que não acreditam neste fato, dizem que a procura por agências físicas pode diminuir devido à maior adesão ao uso da internet nos próximos anos, mas não se extinguir, pois muitos ainda preferem $\mathrm{o}$ atendimento pessoalmente, pela comodidade e pela segurança que a agência remete, mas também colocam a possibilidade das agências físicas se tornarem virtuais, mas sempre mantendo 0 atendimento personalizado, garantindo sua existência no mercado. A maioria dos agentes acreditam que a internet é mais um aliado do que um concorrente, e não substitui um profissional experiente e qualificado; acreditam que a internet é mais usada para a compra de bilhetes aéreos, mas os demais serviços como: compra de diárias em hotéis, receptivos, passeios, são adquiridos através de agências de viagens. Também citam como ponto positivo da agência o contato humano que ela permite, pois o mundo está perdendo este relacionamento que é muito importante, e sua falta desenvolve uma certa carência nas pessoas. Alguns acreditam que o ramo dos agentes está seriamente abalado pelo uso da internet, pois está oferece muitas opções e preços muitas vezes melhores do que a agência, e está terá custos de funcionamento cada vez maiores e serão obrigadas a fechar; outros acreditam que a extinção não ocorrerá, mas que os serviços das agências vão perder bastante espaço para a internet. 
A última pergunta buscou saber se os agentes de viagens acreditam que muitas pessoas utilizam a internet para comprar serviços turísticos. A maioria delas respondeu que passagens aéreas muitas pessoas adquirem pela internet, já que se trata de um meio fácil, rápido e mais barato de compra, visto que em agência são acrescidas taxas e comissões, porém pacotes compram nas agências. Colocaram ainda que acreditam que a maioria utilize a internet apenas como fonte de pesquisa, mas não efetuam a compra por está ferramenta, pela falta de confiança.

Pode-se perceber que de maneira geral os agentes de viagens não se sentem ameaçados pelo uso da internet pelos consumidores de serviços turísticos, porém nas pesquisas realizadas com os próprios consumidores podese perceber que estes estão mais abertos a este tipo de compra do que os agentes imaginam.

Quando indagados se comprariam pacotes de viagens pela internet, 54\% dos entrevistados afirmaram que sim, pela facilidade de compra e de visualizar detalhes, praticidade, rapidez, comodidade, preços melhores e agilidade, dado a falta de burocracia.

Sessenta e cinco por cento dos entrevistados responderam que fazer compras de pacotes de viagens ou mesmo passagem aérea pela internet é fácil e seguro, já que esta apresenta várias opções, e quando adquirido em sites de empresas idôneas não apresenta riscos, já que são seguros e auto-explicativos, a forma de pagamento é facilitada, os preços são mais atrativos, é mais cômodo, prático e ágil, otimiza o tempo, já que não é necessário o deslocamento para a realização da compra, e está pode ser efetivada a qualquer hora.

Quando perguntados sobre se recomendariam a compra de pacotes ou passagens aéreas pela internet, $60 \%$ dos entrevistados disseram que recomendariam a compra em sites seguros de empresas idôneas, que são organizadas e responsáveis, por ser prático, cômodo, rápido (economizando tempo), fácil, não ter burocracia, ser seguro, possibilitar o esclarecimento de dúvidas navegando pela internet, por ter um preço mais baixo e a forma de interessante. $E$ de todos os entrevistados, um público de 36\% já compraram passagens aéreas pela internet.

Estes números revelam que as agências de viagens ainda não estão sendo seriamente afetadas pelas compras realizadas via web, já que os dados acima remetem apenas ao pensamento dos consumidores e não as suas atitudes efetivamente, visto que apenas $22 \%$ dos entrevistados já compraram algum pacote turístico pela internet, e apenas 36\% adquiriram passagens aéreas. $E$ ainda, $54 \%$ dos que responderam a pesquisa disseram que procuram esta prestadora de serviços para realizar suas viagens, e $93 \%$ do total relataram que recomendam os serviços das agências de viagens, já que os vendedores são experientes, profissionais, responsáveis e conhecem os roteiros, podendo esclarecer dúvidas com clareza, dar apoio, orientações, dicas e detalhes sobre bares, restaurantes, atratividades, passeios e roteiros que mais se encaixem nas expectativas de seu cliente, já que oferecem atendimento personalizado. Acreditam que seja prático, seguro e mais cômodo, pois os agentes resolvem tudo para o passageiro, inclusive imprevistos e todas as informações e serviços são prestados em um só lugar, parcelados e sem burocracia.

Porém o número de transações pela internet vem cada dia crescendo, visto que seus preços são melhores e as pessoas estão se familiarizando com está ferramenta, tendo maior confiança em seu uso. Portanto, é importante que os agentes de viagens se atentem a esta mudança, e procurem se adaptar a ela. 


\section{CONSIDERAÇÕES FINAIS}

O uso da internet muda o modo de se trabalhar com o turismo, já que possibilita disponibilizar, amplamente, a informação de maneira rápida, fácil e a baixos custos; as empresas passam a estar mais conectadas a seus clientes e fornecedores, independentemente de sua localização geográfica.

Pode-se verificar sites que vendem produtos turísticos vinte e quatro horas por dia durante todos os dias, a fim de fazer rápidas comparações de preços e produtos.

Tal advento facilita e promove a concorrência, que pode resultar na redução de preços; amplia mercado de atuação; diminui custos de transação na criação, venda e distribuição de serviços.

Permite a qualquer tipo de pessoa a consulta sobre horários, disponibilidade de serviços, cotações de tarifas de serviços turísticos em todo o mundo, reservas de leitos e assentos, venda e emissão de bilhetes aéreos; permite verificar condições do tempo no destino, cotações de moedas, aprender a história, geografia e cultura do local de destino, verificar documentação requerida, ou seja, praticamente tudo que é necessário para a viagem é disposto na internet, possibilitando que as pessoas programem e planejem a viagem sem sair de casa.

Pode-se então diminuição dos custos operacionais e também atingir novos mercados, já que o acesso a informações não requer muito esforço e a facilidade e agilidade no processo de comercialização é grande.

Porém a internet pode muitas vezes disponibilizar informações de má qualidade, causando interpretações errôneas do consumidor.

Seu uso para averiguar e comprar um produto causa a redução do relacionamento humano na comercialização, já que diminuição da margem de intermediação, podendo até mesmo concentrar a venda de serviços em uma grande empresa.

A dificuldade do seu manuseio, falta de tempo para pesquisa, pouca confiança para efetuar pagamento da compra, ausência de contato físico com o produto e também a dificuldade de localização dos produtos na internet são problemas enfrentados por essa ferramenta a fim de penetrar totalmente no mercado.

A internet permite dispor a oferta do produto a praticamente qualquer pessoa, cria curiosidade, agiliza o atendimento e inova o processo de venda, mas reduz e enfraquece o papel da agência e também do agente de turismo que vê suas comissões serem reduzidas pelo uso da internet pelo cliente e se depara com a necessidade de personalizar seu atendimento, criando um diferencial para assim angariar consumidores.

\section{REFERÊNCIAS}

ACERENZA, M. A. Administração do turismo. Bauru: EDUSC, 2002.

ANDRADE, J.V. Turismo: fundamentos e dimensões. 8. ed. São Paulo: Ática, 2001.

ANDRADE, M. M. Introdução à Metodologia do Trabalho Científico. São Paulo: Atlas, 1995.

ANTONIOLI, L. Estatísticas, dados e projeções atuais sobre a internet no Brasil. Disponível em:

<http://www.tobeguarany.com/internet_no_brasil.p hp>. Acesso em: 17 jan. 2010.

BENI, M.C. Análise estrutural do turismo. 6. ed. São Paulo: SENAC, 2001.

BOUDON, R. Os métodos em Sociologia. São Paulo: Ática, 1989.

BRAGA, D.C. Agências de viagens e turismo: práticas de mercado. Rio de Janeiro: Elsevier, 2008.

CARRILHO, B.; VELLANI, M. A importância da internet para o setor hoteleiro. Disponível em: <http://www.faeso.edu.br/horusjr/artigos/Artigo05. pdf>. Acesso em: 18 jan. 2010. 
DANTAS, J.C.S. Qualidade do atendimento nas agências de viagens: uma questão de estratégia. São Paulo: Roca, 2002.

DENCKER, A. F. M. Métodos e técnicas de pesquisa em Turismo.São Paulo: Futura, 1998. Disponível em:

<http://www.discoverybrasil.com/internet>.

Acesso em: 27 jan. 2010.

FLECHA, A.; COSTA, J. I. P.; CARDOSO, O. R. $O$ impacto da internet e o futuro profissional dos consultores de viagem. Revista de Estudos Turísticos, jun./2006. Disponível em: <http://www.etur.com.br/conteudocompleto.asp?| DConteudo=10670>. Acesso em: 12 jan. 2010.

GIL, A. C. Como elaborar projetos de pesquisa. 4.ed.. São Paulo: Atlas, 2007.

LAGO, R. Agências de viagens: desafios de um mercado em reestruturação. Disponível em: $<$ https://www6.univali.br/seer/index.php/rtva/article /view/512>. Acesso em: 12 jan. 2010.

LAKATOS, E. M.; MARCONI, J. Metodologia Científica. São Paulo: Atlas, 2001.

LANZARIN, F. A informação fluida: projetando sítios virtuais para múltiplos dispositivos. Porto Alegre: 2009. Disponível em: <http://www.scribd.com/doc/17587547/AInformacao-Fluida>. Acesso em: 12 jan. 2010.

LENHART, N. L.; CAVALHERO, L. S. S. Comentários à Lei Geral do Turismo (Lei $\mathbf{n}^{\circ}$ 11.771, de 17 de setembro de 2008) e proposições legais para 0 incremento do turismo no país. Brasília: CNC/CCBC, 2008.

LUIZ, V. R. O atual papel das agências de viagens no mercado do turismo brasileiro. Disponível em: <http://www.artigonal.com/turismo-artigos/o-atualpapel-das-agencias-de-viagens-no-mercado-deturismo-brasileiro-1259594.html>. Acesso em: 18 jan. 2010.

MAMEDE, G. Elementos essenciais das agências de viagem e turismo [200-].. Disponível em: <http://www.estig.ipbeja.pt/ ac_direito/agenciasvt. doc>. Acesso em: 25 mar. $201 \overline{0}$.

MANTOVANI, T. M. M.; SOUZA, F. J. As agências de viagens em face das evoluções tecnológicas na era digital. Disponível em: <http://www.fibbauru.br/files/AS\%20AG\%C3\%8A NCIAS\%20DE\%20VIAGENS\%20EM\%20FACE\% 20DAS\%20EVOLU\%C3\%87\%C3\%95ES\%20TEC NOL\%C3\%93GICAS\%20NA\%20ERA\%20DIGITA L.pdf>. Acesso em: 22 mar. 2010.
MENEZES, D. Agências de viagem on line. Disponível em: <http://www.artigonal.com/turismoartigos/agencias-de-viagem-online-964714.html>. Acesso em: 10 mar. 2010.

MELO, P. P. A internet e seus efeitos sobre as empresas de turismo e viagens. Disponível em: <http://www.webartigos.com/articles/9797/1/Globa lizacao-Internet-e-Turismo/pagina1.html>. Acesso em: 17 jan. 2010.

MOREIRA, D. A. Natureza e Fontes do Conhecimento em Administração. Administração On Line, São Paulo, v.1, n. 1,p.01 - 10, 2000.

NEVES, J. L. Pesquisa Qualitativa: características,usos e possibilidades. Caderno de Pesquisas em Administração, São Paulo, v.1, n. 3, p.01-04, 1996.

PETROCCHI, M.; BONA, A. Agências de turismo: planejamento e gestão. 2. ed. São Paulo: Futura, 2003.

RITA, P. A importância do turismo on line. Disponível em: <http://loki.iscte.pt:8080/dspace/bitstream/10071/1 395/1/Rita,+Paulo;+A+Import\%C3\%A2ncia+do+T urismo+On-

line;+RPG;+IIIS\%C3\%A9rie;+Ano16;+N.\%C2\%B

A2;+Lisboa;+ISCTE;+Abr-Mai-

Jun2001;+Partel.pdf>. Acesso em: 12 jan. 2010.

RODRIGUES, W. C. Metodologia científica. Paracambi, 2007.

SEVERINO, A. J. Metodologia do trabalho científico. 23. ed. São Paulo: Cortez, 2007.

TOMELIN, C. A. Mercado de agências de viagem e turismo: como competir diante das novas tecnologias. São Paulo: Aleph, 2001.

VALE, M. S.C.; COSTA, D. C.; ALVES JUNIOR, N. Internet: histórico, evolução e gestão. Disponível em: <http://www.rederio.br/downloads/pdf/nt00501.pdf >. Acesso em: 12 jan. 2010.

VASSOS, T. Marketing estratégico da internet. São Paulo: Makron Books do Brasil, 1998.

VICENTIN, I. C.; HOPPEN, N. O. A internet no negócio de turismo no Brasil: utilizações e perspectivas. Ed. 31. Read, 2003. Disponível em: <http://www.read.adm.ufrgs.br/edicoes/pdf/artigo_ 271.pdf>. Acesso em: 12 jan. 2010. 